\title{
Case Study in SenseCam use as an Intervention Technology for Early-Stage Dementia.
}

\author{
Paulina Piasek*, Kate Irving* and Alan F. Smeaton+ \\ *School of Nursing and Human Sciences \\ +School of Computing and CLARITY: Centre for Sensor Web Technologies \\ Dublin City University \\ Dublin, Ireland
}

This is the Author's post-peer review, accepted paper submitted for final publication by Inderscience and has been published as Piasek, P., Irving, K. and Smeaton, A.F. (2012) 'Case study in SenseCam use as an intervention technology for early-stage dementia', Int. J. Computers in Healthcare, Vol. 1, No. 4, pp.304-319

\begin{abstract}
Dementia is a growing concern with an estimated 41,740 in Ireland and 35.6 million people living with dementia worldwide. In the absence of a medical cure for dementia, pervasive technologies are emerging to support people with dementia. Among such applications is lifelogging, which involves continuously wearing technology to capture a large part of the wearer's life emerging. The recorded data allows clinicians and others to detect behaviour changes or help in memory recall. This study explores the use of SenseCam lifelogging technology as a therapeutic intervention for people with early stage dementia. Based on the principles of Cognitive Stimulation Therapy (CST) it aims to engage them in meaningful discussions about their recent past as captured in the SenseCam images. These discussions offer potential to help maintain the person's identity. The preliminary findings from the first case study highlight some functional issues of SenseCam use within CST principles.
\end{abstract}

Keywords: Dementia, SenseCam, Lifelogging, Cognitive Stimulation Therapy

Introduction: Dementia is a growing concern with an estimated 41,740 people living with dementia in Ireland (Cahill, O'Shea and Pierce 2012) and 35.6 million people living with dementia worldwide (Wimo and Prince 2010). As the population continues to age the number of people with dementia and in need of support will increase. Dementia can be seen as a costly condition, drawing on a variety of public, private, formal and informal resources necessary to provide appropriate care (O'Shea and O'Reilly 2000). It is estimated the overall cost of dementia in Ireland to be just over $€ 1.69$ billion per annum (Cahill, O'Shea and Pierce 2012). The total estimated worldwide costs of dementia is US\$604 billion in 2010 (Wimo and Prince 2010). Dementia is an umbrella term for many different diseases, all of which have similar symptoms, but different aetiologies. The symptoms include a serious loss of cognitive ability including memory, communication and visual beyond that which might be expected from normal aging affecting social activities, relationships or work (American Psychological Association 2001). The diagnosis and staging of dementia is a complex process. The scale for staging of dementia enables approximate classification of the disease, into mild, moderate or severe, with the latter presenting high cognitive impairment and the former very low cognitive impairment (Hughes 1982).

In order to deliver a high standard of care within the financial constraints likely to face health services over the next decade it is essential to develop new strategies that can improve 
independence and quality of life for people with dementia. As currently there is no cure for dementia and early diagnosis and intervention are the expressed aim of every public policy on the disease, a wider range of legitimate supportive options are necessary. Pervasive technologies are emerging to support the person with dementia. There is a wide variety of technologies available to both people with dementia and their carers. They include monitoring and safety technologies, communication and interaction technologies, independence technologies and memory training technologies. Majority are being developed to enhance the well-being and quality of life of people with dementia. Among them is the lifelogging technology predominantly used to detect behaviour changes or test recall of recent memories.

The main purpose of this research is to contribute to the body of knowledge about meaningful interventions in early stage dementia care. The therapeutic potential of using SenseCam technology as an intervention within the principles of CST for people with early stage dementia is explored. CST focuses on strengths and abilities and is careful to avoid situations which erode self-esteem (Spector, et al. 2003). CST as an approach relies heavily on images to generate discussion. We adopted aspects of CST including a framework of 14 sessions running over a seven week period. The sessions have some basis in reminiscence, where meaningful discussion about memories from one's life is the key to interaction, enjoyment, increased contribution and engagement (Spector, et al. 2003). In this instance the images derived from SenseCam are personal to the individual.

SenseCam is a lightweight wearable digital camera which passively takes images of the wearers' activities throughout the day. Instead of a viewfinder/display used to frame photos; SenseCam is fitted with a wide-angle (fish-eye) lens that maximizes the field-of view and is worn on a chord, hanging around the neck so it captures the first-person view, ensuring that nearly everything in the wearer's view is captured (Lee et al. 2008). SenseCam also contains a number of other sensors, including light-intensity, a passive infrared (body heat) detector, accelerometers, and a temperature sensor, which are used together to automatically trigger a photograph to be taken (Lee et al. 2008). SenseCam automatically and passively takes about 3,000 images in a typical day.

This research uses an innovative approach by combining SenseCam images with principles of CST to provide therapeutic intervention aimed at encouraging discussion, improving global cognition and helping to maintain the person's identity.

Background to the study.

The main effects of dementia in the early stages of the disease are typically impairments in memory and the ability to communicate, with short term memory and episodic memory for recent events most significantly impaired. Communication is also affected due to decreased verbal fluency and fear of being incorrect. This often stops the person with dementia from communicating and can lead to social withdrawal, even early on in the disease. Communication is a process of social interaction through which people make sense of themselves and the world around them (Killick and Allan 2001). The ability to relate through communication is essential to constructing narratives about one's memories and making sense of the reality (Clare 2008). It has been further argued that one's sense of identity is represented in the narratives of the past shared with others (McAdams 1996). In order to share these stories one must be able to remember them. This suggests that maintaining the sense of identity by a person with dementia might be problematic as poor memory, decreased communication and social withdrawal often result in inability to share these stories. The erosion of one's sense of identity is very often experienced with the disease progression (Mills 1997). This is one of the most debilitating effects in dementia.

Previous research suggest that SenseCam images mimic episodic memory in being: personal and meaningful to the individual; of recent past, captured from the first person's point of view, 
captured automatically without requiring mindful awareness (Berry, et al. 2007). This study explores whether SenseCam images can represent the person's recent memories and encourage meaningful discussions about them, aiming to help maintain their sense of identity.

Research Objectives.

The main research objective is to collect rich data through the use of case studies, providing insights into the main study questions including:

- Do the images derived from SenseCam represent person's recent past and are they meaningful and enjoyable for the person with dementia?

- Does viewing the images derived from SenseCam encourage rich opinion-based discussion?

- Does viewing the SenseCam images promote interaction between the person with dementia and their relative (carer)?

- Does SenseCam use within the CST framework assist identity maintenance in early stage dementia?

- Does SenseCam use within the CST framework provide any other benefits to the people with early stage dementia?

- Why and how to use SenseCam within Cognitive Stimulation Therapy framework as an intervention for early-stage dementia?

The findings will contribute to the knowledge of meaningful interventions in early-stage dementia care.

Ethical considerations when using lifelogging technology in dementia.

There are some challenges associated with viewing personal images and discussing recent past with participants. These include the participants finding it confronting viewing images of their life that they may not remember. Also they may draw on their life memories or may have view their images negatively, regretfully, as an embarrassment, or for unanticipated reasons may become distressed during the therapy. Moreover some participants may have unhappy (even traumatic) memories which could be triggered by viewing some of the images.

These issues were acknowledged and safeguards set up to deal with such situations and to minimize the risk to the participants. In the event of any of these issues occurring, participants will never be pushed into exposing painful memories against their will. If however, the participant choose to talk further, the therapist enabled them to discuss their distress and helped the individual reflect on the best course of immediate action, including taking a break or discontinuing the therapy. Furthermore, the study uses CST's clear ground rules with the focus not being on remembering specific facts, events, people, personal difficulties or traumatic incidents. Instead, the focus is on pleasurable therapeutic process, stimulating rich opinion rather than fact based discussion. The opinions may be amusing, sad, and unusual but they will never be wrong. Thus, the images are viewed and discussed during the therapy in ethical manner; and a full ethics approval for this research has been granted by Dublin City University Research Ethics Committee.

Both the person with dementia and the carer needed to give consent for themselves by signing the informed consent form in order for the study to begin. Additionally, as the therapy is a continuing process a method of on-going consent was adapted for the person with dementia. This method requires the researcher to assess the person's willingness to participate before each individual session begins. Both verbal and non-verbal signs are taken into attention. Other ethical issues of privacy were also taken into consideration when designing this study. The SenseCam is fitted with a privacy button which disables the automated image capture. The participants are encouraged to use the privacy button when in private places including 
bathrooms, schools, day centres or any other place they may see as private. Participants decided with the help of their carers when they wish to wear the SenseCam and under what social conditions (e.g. alone at home, leisure time activities, socializing with others, etc.). It is also important to note the images captured by the participants were only used for the purposes of the therapy and deleted on its cessation. They are offered to voluntarily give a selection of images for demonstration purposes; this option is specified on the consent form.

The Study: This research is conducted over a 36 month period using an exploratory and descriptive approach: Multiple Case Study method (Yin 2009). During this period the anticipated number of cases explored is three, with the first one completed to date, offering some preliminary findings which are reported below.

Methodology:

This research uses a qualitative in depth case study methodology in order to understand the phenomena of SenseCam use in its context. Three individual case studies were used to collect in-depth data within their context about a complex issue. The richness of the data collected enables answering some of the main questions guiding this study.

A variety of qualitative and quantitative data were used to ensure the issues were explored through multiple lenses. This allows multiple facets of the phenomenon to be revealed. This is an original interpretation of cognitive stimulation and thus needed careful study in order to explore the possibilities of its use and its effects.

Qualitative data includes medical and social history, a tape recorded interview with the carer and the person with dementia before and after the course of the therapy and journals kept by the researcher, the carer and the person with dementia reflecting on observations throughout the sessions from the perspective of the author. Quantitative data includes responses to psychometric measures collected before and after the therapy course. There is evidence that psychometric test responses are important factors to take into consideration in evaluating any therapeutic intervention (Moniz-Cook and Manthorpe 2009). The use of these measures also allows some preliminary comparison of the effect sizes of previous CST research although it must be stressed that any such comparisons will be tentative. Non-parametric tests of repeated measures were used on the quantitative data. The results were then placed in arrays with the qualitative data which were grouped chronologically and thematically. The data is further combined and recombined in several different ways in order to get a thorough understanding of the nuances and the different points of view in each case.

General features of the case studies:

Three individuals with early stage dementia who live with a carer will be recruited. Participants were asked to wear SenseCam every day while they go about their everyday life, over a period of seven weeks. For the period of these seven weeks the therapist and a researcher visited at pre-arranged appointments twice a week, for 45 minutes each time. During this time the therapist viewed the images and engaged the participant in discussions about the images using software which automatically structures the thousands of SenseCam images captured each day, into "events". The event-based browsing software developed in the CLARITY centre (Doherty and Smeaton 2008) allows huge amounts of SenseCam data to be navigated easily. The participant, the carer and the researcher kept a journal each reflecting on observations throughout all sessions during the seven week period. The researcher observed the participant engaging in CST, noting reflections in the journal regarding the process of administration, participant enjoyment and any other comments. A tape recorded interview including responses to standardized measures, medical and social history is undertaken before and after the seven week therapy course. 
The Case of John - Preliminary Findings: The preliminary findings from the first case study highlighted some emerging patterns when using the SenseCam intervention for early stage dementia. By awareness of these patterns the potential benefits of SenseCam intervention can be maximized.

\section{Background}

John was a frail man of eighty-seven. He had a wrinkled face and grey hair, always elegantly parted. His walking pattern was reminiscent of a slow motion film, with his feet barely lifting of the ground. He was a true gentleman always rising up off his chair to greet me and making sure I had a chair to sit down on. He would excuse any little cough or stomach rumble when in my company. John was diagnosed with Alzheimer's disease around three years ago. Despite Alzheimer's being a progressive disease, Mary, his wife and an informal carer informed us he remained in its early stages even when reassessed at his most recent visit at the clinic. His early dementia stage was also confirmed by psychometric measures used in this study including the CDR (Hughes 1982), ADAS-cog (Rosen, Mohs and Davis 1984) and MMSE (Folstein, Folstein and McHugh 1975). John's communication skills were excellent; as he would often initiate the conversation and not only respond to questions but also ask them. This was reflected in the Holden communication measure (Holden and Woods 1995) used to assess how much direction he might need during the therapy. In his before therapy interview he expressed his lifelong passion for sports and world travel. He described what a good tennis player he was but mentioned that now he is only able to play golf. John was an accountant all his life and gave the impression that he enjoyed his work right up until retirement. He was born near the city centre, and then lived abroad for a while until deciding to come back to Ireland. He also revealed he has been married before Mary, however the memory of his past wife seemed somehow avoided and was never explored further.

"I married Mary, my memory is bad I think I have been married to somebody else before. I'd have to ask Mary ehm yes that's my wife Lucy (pointing at a picture)... and that was my first wife and then unfortunately she died." John (Before Therapy Interview)

He was a very positive person and expressed satisfaction with his life on number of occasions during the interview.

“...I have had a happy life I have been lucky... I had a pretty good time” John (Before Therapy Interview)

Mary was in her late sixties, but moved around quickly without any difficulty. The age difference between her and John was noticeable and her silhouette was much bigger than John's. She was indeed very energetic. Mary was the sole informal carer of her husband. In her "before therapy" interview she revealed how over time she needed to take over most of the everyday responsibilities including financial transactions, driving and household chores.

"he doesn't understand what he is leaving ... I remember we went in somewhere and we paid something like eight euro and he gave a fiver tip then I realised I have to take hold of this money so I do all the money now" Mary (Before therapy interview)

Despite Mary being very understanding of her husband's condition and accepting her role as a carer she did express that at times it can be "draining" or "taking a lot out of her". This was reflected by her scoring 5 out of 13 in the psychometric measure of carer strain (with 7 indicating high carer strain). Even though Mary described her and her husband's social life as very active and having quite a big circle of friends, she felt they don't offer to help Mary with 
caring for her husband too often. She did have some support from John's son and his family as they would invite him for an overnight stay on regular basis.

"... I'd love them to say l'll come and visit him for an hour and let you get out. One friend said l'll come and visit you for an hour and that was a year ago he never did..." Mary (Before therapy interview)

The first session

During the initial before therapy interview session I explained how SenseCam works and gave it to John to wear every day for the seven week duration of the therapy. He seemed happy to do that. I left printed instructions in case they needed to go back over them. The principles of CST were also explained. Both John and Mary signed their consent forms and said goodbye until the next visit which was the first therapy session.

On the first therapy session Mary welcomed me into the sitting room and John joined us wearing the camera. Mary told him to pass me the camera and I plugged it into the laptop and started to download the images he collected during the past few days. This turned out to be a long process extending the time of each session by about 45 minutes. Mary sat with anticipation and excitement; John was rather less eager, like half aware of what was going on. I played the pictures and looked through them. John was sitting in silence and Mary kept commenting "hold on now what is that, what were we at?" I'm not sure if John was able to figure out what was on the images or associate them with himself. I tried to engage John by saying it looked like they had a lovely breakfast together and further asking him if he enjoys having breakfast. He responded "oh I think I do, I must have had. I must wait to ask Mary." There was no flooding of memories or Proustian Moments ${ }^{1}$ evoked by the images or breakthrough in communication about his recent past represented in the images. SenseCam images are fairly different from generic photographs as they might seem distorted and out of focus when seen for the first time. Initially I thought John's ability to recognise his past in SenseCam images might improve, however a different pattern emerged as the therapy progressed.

\section{Emerging Patterns:}

1) Severe episodic memory impairment despite the early stage dementia diagnosis.

In the first few sessions it became more and more noticeable that John's episodic memory for recent events was severely impaired. Despite his diagnosis of early stage dementia, confirmed on the psychometric tests used, John could not remember any greater detail of what he had done the day before or even a few hours ago. However, his semantic memory was very well maintained. Initially his ability to communicate at ease and identifying or naming what he had done the day before was misleading to believe that he also has the ability to remember some details about the event. This wasn't the case.

Similarly to the severity of John's recent episodic impairment becoming apparent throughout the sessions, it also became apparent that John couldn't retain memory of what SenseCam is and what it does. Possibly he was simply reminded to wear it by Mary and he had done so every day. It was obvious he may not have had the memory that SenseCam is a camera at times, as on my arrival his wife would have to direct him to "take off that thing hanging around his neck and give it to me" so I could upload the photos. During the therapy when we were viewing the images, most of the time John wouldn't associate the images with himself. He prominently

\footnotetext{
${ }^{1}$ Proustian Moment is an involuntary memory in which cues encountered in everyday life evoke recollections of the past without conscious effort.
} 
associated the images with me - the researcher. This may have occurred because he had no memory of wearing the camera but also because the images were viewed on my laptop, therefore it may have been an obvious thing to presume they are mine.

He would often say:

"That's a great collection you have there"

"Did you stop by and take the photos?" John (Observation field notes)

On occasions when John was reminded that he was the one wearing the camera he often commented "oh I didn't realise I took all the photos". This also showed he didn't retain the memory that SenseCam captures images by itself. On no occasion did he express concern that he was wearing a camera and each time he forgot the research was explained again and he was happy to continue.

The temporary solution was to use a text display area on top of the photographs to remind John he was the one wearing the camera and that the camera took the photos. At the bottom of every picture there was a text stating "John wears the camera which automatically takes

photographs". The SenseCam technology seemed confusing for someone with such severe memory impairments. It also seemed pointless to continuously explain what SenseCam is and that it was John who wore it.

In this particular circumstance John's memory of recent events was so badly affected that he had no memory of wearing the camera. On most occasions this prevented John from recognising the SenseCam images as representations of his past. Thus, the images could not act as cues to discussions about his recent past and help to maintain his identity.

\section{2) John's coping mechanism.}

To cope with his severe memory impairment John relied on Mary in everyday interactions. Initially this became observable throughout the "before therapy" interview when John suggested on few occasions that maybe Mary should also be present. However it really became apparent during the times when I was uploading images onto the laptop and we had general discussions. During these general chats I noticed that whatever direction Mary led the conversation John was happy to follow. Whenever he was asked a question and unsure of the answer he would quickly ask for his wife's help, even if the question asked wasn't a factual question but simply an opinion question. John seemed to have a lower self-confidence and was happy to allow his wife to be in charge. It appeared that John's way of coping with a question or conversation he was uncertain about was to immediately ask for his wife's opinion. Mary was the coping mechanism to his memory impairment. During preparation for one of the sessions we were having general discussions and the therapist was pointing out the window saying "I wonder what's that it looks like a wave". John didn't have enough confidence to state his own opinion and he quickly revert back to his coping strategy and said "I must ask Mary". This coping mechanism used in everyday life by John was transferred into the therapy sessions when SenseCam images were being discussed.

Throughout the therapy sessions the discussions based on SenseCam images viewed presented many questions which John may have seen as challenging. Even if he hadn't much realisation that the images are of events from his own recent past, he was aware that most images are of events in which he took part together with his wife. Anytime he was unsure of something or just low in confidence when it came to his own answer, he would rely on his known coping strategy - his wife. This was illustrated in many situations which were not set out to be challenging but obviously John's low self-confidence resulted in him over relying on his 
wife as a coping strategy. For example on one occasion we were viewing pictures of John and Mary having breakfast when I commented on them to try and engage John in discussion.

I said:

"it looks like you were having a yummy breakfast John?"

to which he responded:

"we must have had, we usually do don't we?" directing his question at Mary.

It was difficult to change John's established coping mechanism (reliance on his wife's memory) and introduce a new one by using SenseCam images. This was especially difficult since Mary was present during most of the sessions thus the easiest solution for John was to ask her as he would do in everyday life rather than use SenseCam images as memory cue.

As this was consistent behaviour during the first few therapy sessions it was decided through supervision meetings to use spaced rehearsal technique (Clare 2005) in order to overcome John's need for reassurance from his wife. The technique worked by measuring the time it took John to ask for reassurance or just to mention his wife during discussions. The first measurement is the time between John initially asking or mentioning his wife to the next, usually 2-3 minutes.

Once the time was recorded I had to build up John's confidence in his ability to discuss the images before the measured time is up. I would say that he is doing well and his ability to describe particular event being discussed is also great. I would repeat that every 2-3 minutes before he asked his wife, and after that I would expand that time space by adding an extra minute or two before building up his confidence again.

The spaced rehearsal technique worked very successfully in the sessions with only John and I present; however it did not work as well with his wife present. Mary answered John's questions some of the times, and then avoid answering other times. This confused John as he didn't understand why he was denied his usual coping strategy when it was within reach. During the sessions when only John and I were present spaced rehearsal technique, extended the time space of John not mentioning his wife up to 25 minutes.

3) Everyday interactions mirrored during therapy.

As the therapy continued it became apparent that similarly to John mirroring his everyday coping mechanism, Mary mirrored her interactions with John from outside of the therapy time into the sessions. This happened despite the clear rules of CST being explained in the plain language statement, prior to and throughout the therapy. According to these CST rules the sessions should be stimulating John in an implicit, passive way rather than via explicit learning, thus reducing any anxiety that could accompany feeling of being 'put on the spot'. The focus was not to be on remembering specific facts, events or people but a pleasurable therapeutic process, stimulating rich opinion rather than fact-based discussion. The everyday interactions between Mary and John weren't guided by these rules and bringing them into the therapy sometimes made it difficult to administer it according to the CST rules.

During the general discussions Mary often asked John about factual details from the day before. These included things like what was the name of the place they visited; the name of the person they have met or where are they heading tomorrow? She also believed in pushing or prompting John if he struggled with his answers. 
"...he can bring them all up only when I push him... not even a cue he just needs to be pushed" Mary ("Before therapy" interview).

If John couldn't remember something, Mary would prompt him further by saying the first letter of the name of the place or a person. John would usually guess the name and Mary would praise him for remembering it. This type of interaction focused on memory of facts and involves putting John on the spot.

Mary mirrored this interaction during the sessions by asking John facts about anything present in the images. This included people, places or objects. During the therapy John was asked by his wife about the name of the person in the image they met a few days before. If John didn't recall the name of that person or got the name wrong this would result in either disappointment or correction by Mary. During the therapy, mirroring this interaction usually resulted in a factbased discussion putting John on the spot rather than allowing him to experience any pleasurable therapeutic process. Thus, factual prompting led to a cycle of negative interactions between Mary and John. These factual questions rarely led to John remembering things in any detail.

Another interaction mirrored from everyday life into the therapy time was correcting John. Mary would often correct John during any chat we had before the therapy started. The corrections ranged in anything from remembering who they visited wrongly to offering tea repeatedly. This is common practice among carers as they aim to help their relative retain the correct memory of recent events. Mary seemed to believe that this "pushing" or prompting as well as correcting John would indeed help him. However during the therapy the focus was to be on opinion-based discussion and not on facts so this was quite a challenge for the research.

Additionally Mary often unintentionally excluded John from a conversation. This was done regularly during everyday conversations and mirrored during the therapy by outpacing him in the speed of conversation. Mary sometimes described something to me and despite John being present in the room she directed all her attention at me and talked at a rather faster pace. John would quickly become disinterested but being the gentleman that he is just wait for Mary to finish without saying anything or asking any questions. She also mirrored this during the therapy when something particularly exciting for her came up in the images. These outbursts of discussions only lasted 5 minutes but happened quite regularly. This could have been due to Mary wanting to share her experiences with someone other than John. One cannot forget that Mary mentioned in the first interview that she missed having someone to chat with. She may at times have seen me as that person and overlook that the focus was meant to be on John's therapy session.

At midpoint of the therapy some feedback was given to both Mary and John. Some of the interactions patterns between Mary and John were discussed and it was reiterated that the therpay required us to to bolster John's confidence by keeping away from fact based discussion and discussing opinions. Since Mary was only present for some of the therapy sessions up until the midpoint it was suggested that maybe she would like to take some time out for herself during the therapy. Based on the "before therapy" interview it was believed that the benefit from therapy may lay in her gaining opportunity for some free time to get out of the house or just a "head-break" when I administered the therapy twice a week. Mary agreed completely as she expressed how she needs some time to relax.

4) The narratives before, during and after the therapy. 
As part of the "before" and "after therapy" interviews John was asked a question aimed to induce a narrative about his life. As mentioned earlier, the theory suggests that it is through sharing these narratives a person creates and maintains their sense of identity (McAdams 1996). The narratives from "before" and "after therapy" interview were then compared to narratives evoked by SenseCam images during the therapy sessions.

John was asked a single question aimed at inducing narrative. This question was based on the biographic interpretive method approach. Within this approach my contribution was limited to this single question initially followed only by not content specific questions. The narratives produced therefore contained only the information John wanted to include in them without much interference from me.

The "before therapy" narrative was rather short and contained only factual information like place and date of birth, school attended and work. The two distinct features of the narrative were the travels around the world and playing a lot of sport. There was a lot of repetition in this narrative as John would mention the sports he played or places he travelled to quite a number of times. The question asked of John was 'tell me your life story including all the events and experiences that were important to you'. The majority of the narrative was based on long distance past as opposed to the recent past. The long-distance past was more elaborative with some clear details as compared to the recent past which was represented in short mentions in between the sentences.

The "after therapy" narrative was similar to the "before therapy" interview in the use of long distance past information however, it was twice as long and contained a lot more detail. John again mentioned his place of birth, school and employment but each was accompanied by a detailed story evoked by memories. This elaboration of the narrative can be interpreted in two ways. Firstly it can be assumed that the therapy could have helped John to use his communication skills and to talk about his memories. Secondly it can be a result of John getting to know me throughout the therapy and feeling more comfortable about discussing his life with me - therefore sharing more details. Both interpretations show positive effects of the therapy. John benefited by practicing his communication skills through sharing his life story and developed some confidence allowing him to share meaningful details of this story. All of the stories were from childhood or young adulthood and none from more recent period of his life. Another similarity to the before therapy narrative was the repression of memory of his late wife. Again, while mentioning his travels John questioned himself if he was married to someone else, before Mary. He got a little confused and again looked at the photograph of his wife. He then remembered that she died and started talking about something else.

Throughout the therapy, there were a few sessions which showed how SenseCam images can evoke memories and lead to meaningful discussions. As the discussions were about John's life they were considered as narratives. It was hoped as suggested by the theory that this re-living of memories would happen regularly during the therapy. However, it was a rather rare occurrence as during most of the sessions John's memory seemed too severely impaired for the images to cue his memories and encourage discussion. On one particular session with just John and I present, I thought it would be interesting to view images from John's social group meeting. John attempted to talk about the group using a framed photo during the previous session. However, he couldn't even remember the name of the group or why they meet.

I started viewing the photographs and explained to John that he was wearing the camera and it took photos. John looked a little bit astonished and asked if he was really wearing the camera. I played the images and asked John to comment on any one that evoked any memories. There were photos from the outside of the building where they meet. The photographs showed John's 
view from the car, step by step while he was approaching the building. John looked rather confused and didn't really recognise the outside of the grounds or the building, but I said that maybe there will be pictures from the inside that he might recognise. In the next few images there was a man who John must have been following. John asked if that was him, so I explained again that it could not have been him as he was the one wearing the camera so it must have been someone he was following.

The minute the browser showed images from the inside of the building John became more alert, there were some pictures of what looked like a cloakroom and I prompted John by saying this must be where everyone leaves their coats. He agreed, however noticed that there is only one coat in the image and normally there is more than that. I wasn't sure whether John was just commenting on the photos or whether he recognised at this point the location and was re-living his memories recognising that normally there are more coats than that. The pictures then showed the meeting room, which John recognised on the first instance without any prompting. He confidently said that this is from his MAN meeting, a name which he previously couldn't remember. He also explained what it stands for. Even though the pictures only showed the room from one viewpoint facing the 'stage' the speaker spot, John went on to describe the rest of the room pointing to the left of the picture, he said that this is where the coffee and tea table is and that normally they would help themselves to it. And that normally there are rows of chairs with many people sitting there and listening to the speaker. He also described what sort of people would normally go to these meetings. This was first real breakthrough in communication and first definite recognition of the pictures and sparking up more memories than what was captured by the photos. This may not be John remembering this specific episode, rather a more established memory of where things normally are during any one of these meetings. However, this was the first session where John actually communicated so confidently about these memories.

He got a little confused as good few photos showed the empty room. I think this was due to John being there earlier than anyone else (explaining why there were only few coats in the cloakroom). He commented that he doesn't understand why he was there on his own. This might be because the SenseCam takes so many photos during a minute that even though the total time could have been 5 minutes all the photos could have made John think it was over a much longer time span. He also commented that the room seems off balance as if on a boat, this is because the SenseCam photos can be taken from a strange angle. John was sitting in the first row of chairs and obviously didn't have memory of that which also confused him as he couldn't see any other rows of chairs in front of him. I tried to explain to him the reasons for each of the above confusions and he seemed to understand and not be bothered about it after that.

Soon after the photos showed the room filling up and John proudly recognised many faces without seeking for any reassurance from Mary. The photos also showed someone giving a presentation and John was also able to identify him and then went onto what different topics people might be discussing. He mentioned holidays or some other hobbies. He then went on to say how everyone can invite someone to give a talk and he said that both of his sons gave a talk but he's unsure what topic were they on. This was purely John's memories sparked up by the photographs. The photos then showed all the men at the bar and John described how they often go for few drinks after and have more chats. The session was hugely successful.

This narrative provided by John with the help of the SenseCam images was very different to the narratives provided before and after the therapy. John was describing his recent past rather than a long distance past. He was able to include details and talk about particulars not captured in the images but related to the event. Compared to John's initiation of description of the group, this narrative encouraged by SenseCam images was very rich in detail. It is unclear why this set of SenseCam images enabled John to provide such detail narrative and other images didn't 
have similar effects. However, it may be assumed it is due to the nature of the images and their importance to John, the functioning spaced retrieval and absence of his other coping strategy Mary.

\section{Conclusion:}

The main objective of this study is to contribute to the knowledge of meaningful interventions in care of people with early-stage dementia. This is accomplished by gaining insight into the study questions by collecting rich data through the use of case studies. Based on individual cases using SenseCam, clear guidelines and reports of how and why to use this technology can be established. SenseCam technology and wearable cameras in general can become a new kind of pervasive care technology for the person with dementia and their carer. This first case study describes some emerging patterns of SenseCam use which need to be considered before exploring further cases.

The case of John using SenseCam offered some insight into the criteria of people with dementia the therapy may be suitable for. Initially it was expected that a diagnosis of early stage dementia would be enough to determine suitability. However, John's case illustrated that despite his early stage dementia confirmed by several psychometric measures his episodic memory of recent events was very severely impaired. The impairment seemed too severe for John to gain the maximum potential benefits from the therapy. In the future cases a different manner of establishing the suitability may have to be deployed. The focus may need to lay more on the memory alone rather than an overall dementia stage. The participant ideally should have some ability to recall recent events in order for the therapy to be suitable. SenseCam and images were also confusing to John as he could not maintain memory of wearing SenseCam or what it does.

Initially it was hoped SenseCam could act as way of encouraging discussions and interactions among the person with dementia and their carer or relative. John's case showed how different coping mechanisms involving the carer can make this a difficult process. Because of John's low self-confidence in his memory and opinions, he had a well-established coping mechanism reliance on Mary's memory. Thus Mary's presence during the therapy made it difficult for John to rely on SenseCam instead of her.

It was further hoped that SenseCam may improve relations among people with dementia and the carers but in this study this wasn't the case. As John and Mary mirrored many everyday interactions into the therapy sessions difficulties emerged with administering the therapy within the CST ground rules. Excluding the carer from therapy sessions resulted in John using images as cues to memory and even encouraged the most open discussions and some narratives about the events. The carer benefited by using therapy time as "head-space" or free time. The idea of excluding the carer needs to be explored further on case to case basis.

The narratives during the therapy were very different to the ones before and after the therapy. A possible change of methodology used to induce the narrative during the "before" and "after therapy" interview may be considered. Instead of asking a biographical question, more current questions about the person's life may be asked. This should allow greater comparison of the amount of details mentioned in the narratives with or without the use of SenseCam images.

The psychometric tests showed no differences in the scores from before and after the therapy, on any of the measures including quality of life, anxiety, depression, carer strain and communication. 
These patterns provide insight into some of the main study questions. The questions cannot be fully addressed until all three case studies are completed however; some understandings were gathered from the perspective of this case study. The opinion-based discussions encouraged through SenseCam images were rather a rare occurrences. The sessions didn't promote interactions between the person with dementia and the carer. At times SenseCam use within the CST framework assisted the person with dementia in producing narratives which help to maintain their identity. Other benefits to the people with early stage dementia noted in this study included enjoyment and cognitive stimulation. Future case studies should help to answer why and how to use SenseCam within CST framework as an intervention for early-stage dementia.

This study used an innovative approach to provide a therapeutic intervention by combining SenseCam images with principles of CST. The main aim of CST is to stimulate cognition globally through a range of meaningful discussions. In this case SenseCam didn't stimulate as many discussions as anticipated, due to John's severe episodic memory impairment.

Additionally, some other issues in using SenseCam within CST were highlighted. However, SenseCam intervention did support some of the main principles of CST. They included: mentally stimulating and challenging John, encouraging opinion based rather than fact based discussions, maximising his potential by providing prompts in the form of SenseCam images, and creating consistency and continuity between sessions.

These preliminary findings are from the first out of the three case studies. Once the issues highlighted in this case study are addressed in the future case studies the potential of SenseCam to support CST should increase. Using the case study methodology allows for aspects of SenseCam use as a therapy for people with dementia to be described in greater detail. This highlights some emerging patterns with SenseCam use as well as aspects of overall processes of administration of the therapy. By acknowledging these issues in the next case studies there is a potential for maximizing benefits of SenseCam use as pervasive care technology for people with dementia and their carers.

\section{References.}

American Psychological Association. 2001. Statistical Manual of Mental Disorders. 5th ed. Washington, DC: American Psychological Association.

Berry, E., Kapur, N., Williams, L., Hodges, S., Watson, P., Smyth, G., Srinivasan, J., Smith, R., Wilson, B. and Wood, K. 2007. The use of a wearable camera, SenseCam, as a pictorial diary to improve autobiographical memory in patient with limbic encephalitis: A preliminary report. Neuropsychological Rehabilitation, 17(4-5), pp.582-601.

Cahill, S., O'Shea, E. and Pierce, M. 2012. Creating excellence in dementia care: A Research Review for Ireland's National Dementia Strategy. Ireland: Department of health. Health Service Executive.

Clare, L. 2005. Cognitive Rehabilitation for People with Dementia IN: Marshall, M. (ed.) Perspectives on Rehabilitation and Dementia. London: UK Jessica Kingsley Publishers, pp.180.

Clare, L. 2008. Neuropsychological rehabilitation and people with dementia. Hove, East Sussex ; New York, NY: Psychology Press. 
Doherty, A.R. and Smeaton, A.F. 2008. Automatically Segmenting LifeLog Data into Events. IN: WIAMIS 2008 - 9th International Workshop on Image Analysis for Multimedia Interactive Services. Klagenfurt, Austria: WIAMIS.

Folstein, M.F., Folstein, S.E. and McHugh, P.R. 1975. Mini-mental state: A practical method for grading the cognitive state of patients for the clinician. Journal of Psychiatric Research, 12(3), pp.189-198.

Hughes, C.P. 1982. A new clinical scale for the staging of dementia. British Journal of Psychiatry, 140pp.566-572.

Killick, J. and Allan, K. 2001. Communication and the care of people with dementia.

Buckingham ; Philadelphia, Pa: Open University Press.

Lee, H. Smeaton, A.F. O'Connor, N.E. Jones, G. Blighe, M. Byrne, D. Doherty, A. and Gurrin, C. 2008. Constructing a SenseCam visual diary as a media process. Multimedia Systems. $14(6)$ pp. 341-349.

McAdams, D.P. 1996. Personality, modernity, and the storied self: A contemporary framework for studying persons. Psychological Inquiry, 7(4), pp.295-321.

Mills, M.A. 1997. Narrative identity and dementia: a study of emotion and narrative in older people with dementia. Ageing and Society, 17(6), pp.673-698.

Moniz-Cook, E. and Manthorpe, J. 2009. Early Psychosocial Interventions in Dementia: Evidence-Based Practice. London: Jessica Kingsley Publishers.

O'Shea, E. and O'Reilly, S. 2000. The economic and social cost of dementia in Ireland. International Journal of Geriatric Psychiatry, 15(3), pp.208-218.

Rosen, W.G., Mohs, R.C. and Davis, K.L. 1984. A new rating scale for Alzheimer's disease. The American Journal of Psychiatry, 141(11), pp.1356-1364.

Spector, A., Thorgrimsen, L., Woods, B., Royan, L., Davies, S., Butterworth, M. and Orrell, M. 2003. Efficacy of an evidence-based cognitive stimulation therapy programme for people with dementia. British Journal of Psychiatry, 183(3), pp.248-254.

Wimo, A. and Prince, M. 2010. World Alzheimer Report 2010 The Global Economic Impact of Dementia. Alzheimer's Disease International (ADI ).

Yin, R.K. 2009. Case Study Research: Design and Methods. 4th ed. Thousand Oaks, Calif.: Sage Publications. 